\title{
The early prognosis value of activin $A$ in premature infants' brain injury
}

\author{
Ahmad Daniyal Shahid ${ }^{1 \star}$, Haitao $\mathrm{Zhu}^{2}$, Hong Yan $\mathrm{Lu}^{2}$, Ming Chang ${ }^{2}$, Abdul Malik ${ }^{1}$, Murad Ali \\ Sher ${ }^{1}$ and Walid Ullah Adil ${ }^{1}$
}

${ }^{1}$ School of Medicine, Jiangsu Universtiy, Jiangsu, Zhenjiang, P. R. China, 212013.
${ }^{2}$ Department of Pediatrics, Affiliated hospital of Jiangsu University, Jiangsu, Zhenjiang, P. R. China, 212013.

Accepted 27 March, 2017

\begin{abstract}
The purpose of this research is to explore the predictive value of amniotic fluid, umbilical cord blood and neonatal blood activin A in early brain injury in preterm neonates. 98 cases of premature infants were divided into brain injury group and control group according to the cranial imaging examination, and the brain injury group was further divided into mild brain injury group and severe brain injury group. The activin A level was measured in both preterm brain injury group and control group with enzyme-linked immunosorbent assay (ELISA) kit, then the comparisons of activin A levels between brain injury group and control group, mild and severe brain injury group were implemented to find out their differences. The results demonstrated that activin A levels of umbilical cord blood, amniotic fluid and 3-day-old premature infant peripheral blood in brain injury group were significantly higher than the control group $(P<0.05)$, activin $A$ levels of amniotic fluid, umbilical cord blood and 3-day-old infant blood in the severe brain injury group were significantly higher than the mild brain injury group $(P<0.05)$, intragroup comparison among the brain injury group showed amniotic fluid and 3-day-old premature infant serum activin A levels were significantly higher than umbilical cord blood $(P<0.05)$, activin $A$ has a certain value in early prediction and severity assessment of preterm brain injury.
\end{abstract}

Keywords: Activin A, severity levels, preterm neonates, intraventricular hemorrhage, periventricular leucomalacia.

*Corresponding author. E-mail: asifwali_khan@yahoo.com.

\section{INTRODUCTION}

Many hopeful researchers aim to decrease the amount of further preterm brain injury by using bio-markers in prognosis. The need for early prognosis is paramount since knowing the extent of the preterm brain injury allows physicians to act accordingly. Many bio-markers such as s100B, activin A, erythropoietin, chemokine ligand 18 (CCL 18), glial fibrillary acidic protein (GFAP) and neurofilament light chain (NFL) are intriguing to researchers seeking ideal bio-markers. Activin $A$ is a growth factor composed of two $\beta A$ subunits belonging to the transforming growth factor $\beta$ (TGF- $\beta$ ) superfamily of dimeric proteins. Furthermore, it is reported that activin $A$ has strong neuroprotective activities (Florio et al., 2007). Neuronal cells have high density of activin A receptors which up-regulate activin mRNA expression (He et al.,
2012). In vivo, activin A is neuroprotective during excitotoxic brain injury, also, the research shows that preterm infants which later developed IVH have higher levels of plasma activin A, and higher levels of activin A are seen in the term infants with moderate and severe asphyxia (Mukerji et al., 2007). Activin A concentration in maternal serum increases with progressive gestational age and reaches its peak near term; spontaneous labor and vaginal delivery also bring dynamic changes in the activin A levels (Boyce et al., 1999; Whitaker et al., 1996). Premature birth is the leading cause of intraventricular hemorrhage (IVH) in preterm nenoates , the hypoxic injury to the capillaries of subependymal germinal matrix and subventricular zone leads to bleeding into ventricular system and cause long-term 
impaired neurological development (Wilson-Costello et al., 2005; Volpe et al., 1995, 2008). Extremely low birth weight preterm neonates are at higher risk of IVH and periventricular leukomalaica (PVL) resulting in impaired neurological and physiological development (Bassan, 2009). Infants with grade I and grade II IVH have less severe neurological impairments than those who developed parenchymal lesions or ventriculomegaly, infants with grade III to IV are more prone to severe delay in neurological and physiological development (Hack et al., 2000; Boyce et al., 1999). IVH can persist without any clinical presentations in up to $50 \%$ of the preterm neonates; even so, newborns with severe IVH can present bulging fontanel, apnea, pallor, seizure and altered level of cognitive state (Wilson-Costello et al., 2005). PVL is an ischemic induced injury to oligodendrocytes of the periventricular white matter (O'Shea et al., 1998; Holcroft et al., 2003; Graham et al., 2004). Severity of the neurological insult is directly related to the seriousness of PVL which is associated with reduction in volume of thalamus, cortex and basal ganglia (Whitaker et al., 1990; Volpe et al., 2011). Over time the injured area of the brain form cysts, cystic PVL confirmed with ultrasound images is an indication of cerebral palsy (Bouvier et al., 2011; Bass, 2011). PVL accounts for $90 \%$ of the neurological deficits which includes cognitive dysfunction, cerebral palsy, blindness, loss of hearing, and impaired psychological and physiological development in surviving preterm neonates (Galli et al., 2004; Gazzolo et al., 2003).

However, limited information is available concerning the prognosis of brain injury using activin $A$ as bio-marker. Therefore, the aim of this study was to evaluate activin $A$ levels in amniotic fluid, cord blood and $3^{\text {rd }}$ day peripheral blood of preterm neonates and find a correlation between activin A level and severity of neural insults in brain injury group.

\section{MATERIALS AND METHODS}

\section{General materials}

The objectives of study are premature infants (gestational age $<34$ weeks) born in the affiliated hospital of Jiangsu university between August 2015 and September 2016.

Exclusive criteria comprised of following cases: (1) Mothers with infectious diseases; (2) The preemies with following diseases: hereditary metabolic disorder, congenital deformity of the nervous system, congenital deformity of other physiological systems. All the studies were approved by the ethics committee of the Affiliated Hospital of Jinagsu University and informed consent was obtained from the parents of each infant.

\section{Classification of IVH and PVL}

The classification of IVH was according to Papile grading approach (Papile et al., 1978). Grade I unilateral or bilateral subependymal germinal matrix hemorrhage; Grade II Subependymal hemorrhage broached out and leading to intraventricular hemorrhage, 10 to $50 \%$ of ventricular area on sagittal view without ventricular enlargement; Grade III Intraventricular hemorrhage associated with ventricular enlargement; Grade IV Intra-parenchymal echodensity (IPE) represents periventricular hemorrhagic infarction and is often referred to as Grade IV IVH.

Grade I-II are regarded as mild IVH, grade III-IV are regarded as severe IVH.

The classification of PVL was according to De Vries grading approach (de Vries et al., 1992) Grade I Transient periventricular ECHODENSITIES were continued for more than 7 days but no cystic lesions were formed; Grade II transient echo enhancement of periventricular thenceforth confirmed small evolving localized fronto-parietal cysts;

Grade III extensive echo enhancement of periventricular thenceforth showed small cystic lesions, evolving into extensive periventricular cystic lesions involving the occipital and frontoparietal white matter; Grade IV extensive echodensities of periventricular involved subcortical superficial white matter, thenceforth confirmed diffused cystic lesions of periventricular and subcortical superficial white matter.

Grade I-II is regarded as mild PVL and grade III-IV is regarded as severe PVL.

\section{Detection of activin A in blood serum and amniotic fluid}

$2 \mathrm{ml}$ of amniotic fluid was collected by puncturing with aseptic technique right before delivery. $2 \mathrm{ml}$ of venous cord blood was collected with a syringe and treated with heparin before the preemie established first autonomic breath after delivery. $2 \mathrm{ml}$ peripheral venous blood was collected after the $3^{\text {rd }}$ day of delivery. All the above-mentioned samples were put in test tubes at room temperature for $0.5 \mathrm{~h}$, and then centrifuged for $10 \mathrm{~min}$ at 3000 $\mathrm{r} / \mathrm{min}$, the supernatant fluids were kept in $-80^{\circ} \mathrm{C}$ refrigerator for the following detection. The detection of activin $A$ in blood serum and amniotic fluid was made through Enzyme-Linked Immunosorbent Assay (ELISA) method, the ELISA Kit was obtained from RayBiotech and performed according to the manufacture's protocol.

\section{Imaging examination of brain injury on the premature infants}

All the premature infants were put through the first imaging examination using type-B ultrasonic technique after the $3^{\text {rd }}$ day of birth and follow-up checks every other week before hospital discharge. The infants whose type-B ultrasonic examination results were in normal range but were suspected of brain injury were put through CT and MRI examination, which confirmed the brain injury. The grades of premature infants' brain injury were clarified as: $(A)$ Intracranial hemorrhage, include; IVH, PVL; (B) Other injuries such as cerebral infarction, etc.

Infants with one of above diseases were taken in brain injury group.

\section{Statistical analysis}

All statistical analyses were conducted with SPSS 16.0 statistical software. All grouped data was processed and presented as mean \pm standard deviation $(\bar{x} \pm \mathrm{s})$. T-test or $x^{2}$-test was employed to determine the significant differences between means at a significant level $(p<0.05)$.

\section{RESULTS AND DISCUSSION}

A total of 98 premature infants were included in this 
study, including 57 males and 41 females, mean birth weight was $1928 \pm 331 \mathrm{~g}$, mean gestational age was 32.6 \pm 1.2 weeks. According to the results of brain imaging examination, the cases were divided into two groups: 60 cases in the control group and 38 cases in the brain injury group. The brain injury group include 23 IVH cases, of which 17 cases of mild IVH and 6 cases of severe IVH; 10 PVL cases in brain injury group of which 8 cases of mild PVL and 2 cases of severe PVL; the rest of 5 brain injury cases include 3 cases of cerebral hemorrhage, 1 case of cerebellar hemorrhage and 1 case of cerebral infarction. There was no significant difference in gender, birth weight, and gestational age between the two groups $(P>0.05)$ (Table 1).

\section{Comparison of activin A between control group and case group}

Compare with control group, the serum activin A levels of amniotic fluid, cord blood and 3 day old infants' peripheral blood in case group were significantly higher than the non brain injury group, the differences were statistically significant $(P<0.05)$. Intragroup comparison showed that 3 days old infants' peripheral blood serum activin A levels and amniotic fluid activin A levels were higher than cord blood, the differences were statistically significant $(P<0.05)$. Intragroup comparison showed no significant difference of activin $A$ levels in control group $(P>0.05)$ (Table 2).

\section{Comparison between mild brain injury group and severe brain injury group of serum activin A levels}

Mild IVH and PVL are classified as mild brain injury and severe IVH and PVL are classified as severe brain injury groups. The comparison results among amniotic fluid, cord blood, 3 day old infants' peripheral blood showed that serum activin A levels of severe brain injury group were significantly higher than that of mild brain injury group. The differences were statistically significant $(P<$ 0.05) (Table 3).

Table 1. Comparison of general situation between control group and case group $(\bar{x} \pm \mathrm{s})$.

\begin{tabular}{|c|c|c|c|c|c|}
\hline \multirow{2}{*}{ Groups } & \multirow{2}{*}{ Cases } & \multicolumn{2}{|c|}{ Gender } & \multirow{2}{*}{ Birth weight (g) } & \multirow{2}{*}{ Gestational age (week) } \\
\hline & & Male & Female & & \\
\hline Control group & 60 & 34 & 26 & $1930 \pm 322$ & $32.7 \pm 1.1$ \\
\hline Cases group & 38 & 23 & 15 & $1925 \pm 350$ & $32.3 \pm 1.2$ \\
\hline$T\left(x^{2}\right)$ value & \multicolumn{3}{|c|}{$(0.142)$} & 0.061 & 1.870 \\
\hline$P$ value & & \multicolumn{2}{|c|}{0.706} & 0.952 & 0.065 \\
\hline
\end{tabular}

Table 2. Comparison of activin A levels between control group and case group $(\bar{x} \pm \mathrm{s})$.

\begin{tabular}{lcccc}
\hline Groups & Cases & Cord blood $(\mathbf{n g} / \mathbf{d l})$ & Amniotic fluid $(\mathbf{n g} / \mathbf{d l})$ & $\mathbf{3}^{\text {rd }}$ day peripheral blood $(\mathbf{n g} / \mathbf{d l})$ \\
\hline Control group & 60 & $24.20 \pm 6.11$ & $25.78 \pm 6.59$ & $25.206 \pm 5.92$ \\
Cases group & 38 & $29.20 \pm 4.62$ & $32.57 \pm 7.03$ & $31.55 \pm 5.16$ \\
& & & \\
$T\left(X^{2}\right)$ value & & 4.317 & 4.842 & 5.434 \\
$P$ value & & $<0.05$ & $<0.05$ & $<0.05$ \\
\hline
\end{tabular}

Note: Intragroup comparison of cord blood activin A levels among the control group showed $(p>0.05)$ - Intragroup comparison of cord blood activin $A$ levels among the case group showed, $P<0.05$.

Table 3. Comparison of activin A levels between severe brain injury group and mild brain injury group $(\bar{x} \pm \mathrm{s})$.

\begin{tabular}{lcccc}
\hline Groups & Cases & Cord blood $(\mathbf{n g} / \mathbf{d l})$ & Amniotic fluid $(\mathbf{n g} / \mathbf{d l})$ & $\mathbf{3}^{\text {rd }}$ day peripheral blood $(\mathbf{n g} / \mathbf{d l})$ \\
\hline Mild brain injury group & 25 & $27.99 \pm 4.66$ & $30.38 \pm 6.34$ & $29.57 \pm 4.80$ \\
Severe brain injury & 8 & $32.69 \pm 3.76$ & $38.85 \pm 6.91$ & $37.10 \pm 2.48$ \\
& & & \\
$T$ value & & 2.589 & 3.220 & 4.222 \\
$P$ value & & $<0.0001$ & $<0.003$ & $<0.0003$ \\
\hline
\end{tabular}




\section{DISCUSSION}

Activin $A$ is neuroprotective during excitotoxic brain injury and activin $A$ regulates spine formation, behavioral activity, late-phase long-term potentiation, maintenance of memory and adult neurogenesis ( $\mathrm{He}$ et al., 2012; Mukerji et al., 2007). First expressions of activin A are seen in ischemic cerebral cortical neurons of neonatal rat model with hypoxic-ischemic brain damage (Florio et al., 2010). Activin A has protective effects on the neurons of neonate rats with hypoxic-ischemic brain injury (An et al., 2006). The current study found that the preterm neonates in the injury group suffering from IVH and PVL have significantly higher levels of activin $A$ in umbilical cord blood than the control group $(p<0.05)$. The fast decline in the maternal serum activin $A$ levels after the placental delivery suggest that the placenta is the main source of activin A protein in maternal serum and fetal blood (Sutton and Darmstadt, 2013). This study also found that preterm neonates in the brain injury group suffering from IVH and PVL have significantly high activin $A$ level in amniotic fluid as compared to the control group with no brain injury $(p<0.05)$. Activin $A$ is found abundantly in fetal membranes of amnion and chorion, which explains the high concentrations of activin A protein in the amniotic fluid (Petraglia et al., 1991; Wallace, 1997).

The current study observed significantly high activin A level in $3^{\text {rd }}$ day peripheral blood of preterm neonates suffering from IVH and PVL as compared to the control group $(p<0.05)$. Throughout the gestational age activin $A$ is released into maternal serum, amniotic fluid and fetal blood through umbilical vein, showing highest concentrations of activin A at term (Petraglia et al., 1993, 1997; Muttukrishna et al., 1996). After traumatic brain injury in premature infants increased endogenous expression of activin $A$ is presumably associated with tissue injury, inflammation and repair (Sannia et al., 2013). Given the inflammation induced, activin A affects and inhibit the inflammatory response (Jones et al., 2007). Activin A forecast hypoxicischemic encephalopathy (HIE) sensitivity of $93.33 \%$ and specificity of $96.63 \%$ (Huang et al., 2016), activin A levels of amniotic fluid, umbilical cord blood and $3^{\text {rd }}$ day peripheral blood of preterm neonates in the severe brain injury group were significantly higher than in the mild brain injury group $(P<0.05)$, intragroup comparison among the brain injury group shows that amniotic fluid and $3^{\text {rd }}$ day peripheral blood activin A levels of preterm neonates are significantly higher than the cord blood activin $A$ level $(P<0.05)$. The study suggest that activin $A$ is a useful bio-marker in the early prediction of brain injury in preterm neonates, while showing a strong correlation between high activin A level and severity of brain injury. Neonatal as well maternal serum activin $A$ levels for monitoring brain injury progress can evaluate a new direction for the prognosis of brain injury. We hope that this research will inspire others to improve this study or create an actual usable system implementing bio- markers.

\section{Conclusion}

To sum it up, significantly high activin A levels in umbilical cord blood and amniotic fluid may have a certain value for the early prediction and severity assessment of brain injury in preterm neonates.

\section{REFERENCES}

An L, Wang $X Y, W u$ J, 2006. Protective effects of activin on the neurons of neonatal rats with hypoxic ischemic brain injury. J Child Neurol, 20(7): 582-587.

Bass WT, 2011. Periventricular leukomalacia. NeoReviews, 12(2): e76e84.

Bassan H, 2009. Intracranial hemorrhage in the preterm infant: understanding it, preventing it. Clin Perinatol; 36(4): 737-62.

Bouvier D, Castellani C, Fournier M, Dauphin JB, Ughetto S, Breton M, Labbé A, Weinberg AM, Sapin V, 2011. Reference ranges for serum S100B protein during the first three years of life. Clin Biochem, 44: 927-929.

Boyce GC, Smith TB, Casto G, 1999. Health and educational outcomes of children who experienced severe neonatal medical complications. J Genet Psychol, 160(3): 261-269.

de Vries LS, Eken P, Dubowitz LMS, 1992. The spectrum of leukomalacia using cranial ultrasound. Behav Brain Res, 49(1): 1-6.

Florio P, Frigiola A, Battista R, Abdalla Ael H, Gazzolo D, Galleri L, Pinzauti S, Abella R, Li Volti G, Strambi M, 2010. Activin A in asphyxiated full-term newborns with hypoxic ischemic encephalopathy. Front Biosci (Elite Ed), 1;2: 36-42.

Florio P, Gazzolo D, Luisi S, Petraglia F, 2007. Activin A in brain injury. Adv Clin Chem, 43: 117-130.

Galli KK, Zimmerman RA, Jarvik GP, Wernovsky G, Kuypers MK, Clancy RR, Montenegro LM, Mahle WT, Newman MF, Saunders AM, Nicolson SC, Spray TL, Gaynor JW, 2004. Periventricular leukomalacia is common after neonatal cardiac surgery. J Thorac Cardiovasc Surg, 127(3): 692-704.

Gazzolo D, Bruschettini M, Corvino V, Lituania M, Sarli R, Bruschettini P, Michetti F, 2003. Amniotic fluid levels of S100B protein in normal and trisomy-21 foetuses. Clin Chim Acta, 330: 131-133.

Graham EM, Holcroft CJ, Rai KK, Donohue PK, Allen MC, 2004. Neonatal cerebral white matter injury in preterm infants is associated with culture positive infections and only rarely with metabolic acidosis. Am J Obstet Gynecol, 191(4): 1305-1310.

Hack M, Wilson-Costello D, Friedman $H$, Taylor HG, Schlucter M, Fanaroff AA, 2000. Neurodevelopment and predictors of outcomes of children with birth weights of less than $1000 \mathrm{~g}$ : 1992-1995. Arch Pediatr Adolesc Med, 154(7): 725-731.

He JT, Mang J, Mei CL, Yang L, Wang JQ, Xing Y, Yang H, Xu ZX, 2012. Neuroprotective effects of exogenous activin $A$ on oxygen-glucose deprivation in PC12 cells. Molecules, 17(1): 315-327.

Holcroft CJ, Blakemore KJ, Allen M, Graham EM, 2003. Association of prematurity and neonatal infection with neurologic morbidity in very low birth weight infants. Obstetrics and Gynecology, 101(6):12491253.

Huang W, Lu H, Wang Q, Chang M, Zhang Q, 2016. Activin A predicts brain injury in preterm neonates (In Chinese).

Jones KL, Mansell A, Patella S, Scott BJ, Hedger MP, de Kretser DM, Phillips DJ, 2007. Activin A is a critical component of the inflammatory response, and its binding protein, follistatin, reduces mortality in endotoxemia. Proc Natl Acad Sci U S A, 104(41): 16239-16244.

Mukerji SS, Katsman EA, Wilber C, Haner NA, Selman WR, Hall AK, 2007. Activin is a neuronal survival factor that is rapidly increased after transient cerebral ischemia and hypoxia in mice. $J$ Cereb Blood Flow Metab, 27(6): 1161-1172.

Muttukrishna S, Fowler PA, George L, Grmme NP, Knight PG, 1996. Changes in peripheral serum levels of total activin A during menstrual 
cycle and pregnancy. J Clin Endocrinol Metab, 81(9): 3328-34.

O'Shea TM, Klinepeter KL, Meis PJ, Dillard RG, 1998. Intrauterine infection and the risk of cerebral palsy in very low-birth weight infants. Paediatr Perinat Epidemiol, 12(1): 72-83.

Papile LA, Burstein J, Burstein R, Koffler $H$, 1978. Incidence and evaluation of subependymal and intraventricular hemorrhage: a study of infants with birth weight less than $1500 \mathrm{~g}$. J Pediatr, 92(4): 529-534.

Petraglia F, Gag S, Florio P, 1993. Activin A and activin B measured in maternal serum, cord blood serum and in amniotic fluid during human pregnancy. Endocr J, 1: 323-327.

Petraglia F, Garuti GC, Calza' L, Roberts V, Giardino L, Genazzani AR, Vale W, Meunier $\mathrm{H}$, 1991. Inhibin subunits in human placenta: localization and messenger ribonucleic acid levels during pregnancy. Am J Obstet Gynecol 165(3): 750-758.

Petraglia F, Luisi S, Benedetto C, Zonca M, Florio P, Casarosa E, Volpe A, Bernasconi S, Genazzani AR, 1997. Changes of dimeric inhibin B levels in maternal serum throughout healthy gestation and in women with gestational diseases. J Clin Endocrinol Metab, 82(9): 2991-2995.

Sannia A, Zimmermann LJ, Gavilanes AW, Vles HJ, Calevo MG, Florio P, Gazzolo D, 2013. Elevated activin A urine levels are predictors of intraventricular haemorrhage in preterm newborns. Acta Paediatr, 102(10): e449-454.

Sutton PS, Darmstadt GL, 2013. Preterm birth and neurodevelopment: a review of outcomes and recommendations for early identification and cost-effective interventions. J Trop Pediatr, 59(4): 258-265.

Volpe JJ, 1995. Intracranial hemorrhage: germinal matrixintraventricular hemorrhage of the premature infant: neurology of the newborn. (Philadelphia: W.B. Saunders).

Volpe JJ, 2008. Neurology of the Newborn. 5th Edition, Elsevier.

Volpe JJ, Kinney HC, Jensen FE, Rosenberg PA, 2011. The developing oligodendrocyte: Key cellular target in brain injury in the premature infant. Int J Dev Neurosci, 29(4): 423-440.

Wallace EM, Riley SC, Crossley JA, Ritoe SC, Horne A, Shade M, Ellis PM, Aitken DA, Groome NP, 1997. Dimeric inhibins in amniotic fluid, maternal serum and fetal serum in human pregnancy. $J$ Clin Endocrinol Metab, 82(1): 218-222.

Whitaker AM, Feldman JF, Van Rossem R, Schonfeld IS, Pinto-Martin JA, Torre C, Blumenthal SR, Paneth NS, 1996. Neonatal cranial ultrasound abnormalities in low birth weight infants: Relation to cognitive outcomes at six years of age. Pediatrics, 98: 719-729.

Whitaker AM, Johnson J, Sebris S, Pinto J, Wasserman G, Kairam R, Shaffer D, Paneth N, 1990. Neonatal cranial ultrasound abnormalities association with developmental delay at age one in low birth weight infants. J Dev Behav Pediatr, 11(5): 253-260.

Wilson-Costello D, Friedman H, Minich N, Fanaroff AA, Hack M, 2005. Improved survival rates with increased neural developmental disability for extremely low birth weight infants. Pediatrics, 115(4): 997-1003.
Citation: Shahid AD, Zhu H, Lu HY, Chang M, Malik A, Sher MA, Adil WU, 2017. The early prognosis value of activin $A$ in premature infants' brain injury. Int Res J Med Med Sci, 5(2): 14-18. 